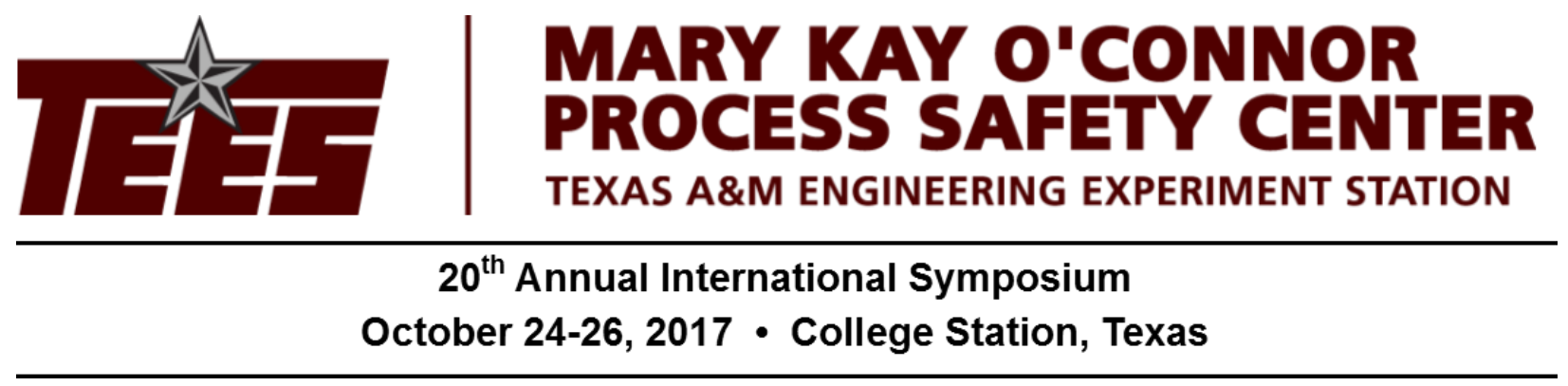

\title{
Containing Hydrogen Deflagrations
}

\author{
Michael S. Schmidt \\ Engineering Management Department and Chemical Engineering Department \\ Missouri University of Science and Technology \\ Rolla, Missouri 65409, USA \\ Bluefield Process Safety, LLC \\ Saint Louis, Missouri 63118, USA \\ bluefieldsafety@gmail.com
}

\begin{abstract}
Schroeder and Holtappels (2005) published data on the explosion characteristics of hydrogen-air mixtures, looking at the effect of pressure and temperature on upper and lower explosive limits and the effect of pressure, temperature, and composition on explosion ratio, $\mathrm{P}_{\mathrm{EX}} / \mathrm{P}_{\mathrm{O}}$. They showed that the effect of increasing pressure on UEL and LEL is negligible to slightly advantageous, while the effect of increasing temperature was disadvantageous. They also showed that the explosion ratio was largely independent of operating pressure, but very dependent on temperature and composition of hydrogen-air mixtures. However, they did not develop their data to the point that it could be used as the basis of design and risk assessment.

This paper uses the data published by Schroeder and Holtappels to develop equations that can be used to predict the extent of a hydrogen-air deflagration in a vessel and correlates those predictions to the nature of pressure vessel failures that are likely to be experienced as a result of such a deflagration.
\end{abstract}

Keywords

Containment, Deflagration, Equipment design data

\section{Hydrogen Is Dangerous}

Hydrogen is the most common element in the universe. As a molecule, $\mathrm{H}_{2}$ is colorless, odorless, and tasteless. It is not toxic, not a carcinogen, and has no threshold limit value. Nonetheless, it is dangerous for a number of reasons. It is an asphyxiant. It is frequently used as a cryogen. It causes hydrogen embrittlement. Also, hydrogen is very flammable, burning easily to form water. 
While non-toxic, it is not air, so it is a simple asphyxiant. People will feel adverse effects of a hydrogen release when it forces the oxygen concentration in the gas they are breathing to less than $19 \%$. When a release of hydrogen forces the oxygen concentration to less than $10 \%$, people will become unable to move, lose consciousness, and suffer convulsions. At an oxygen concentration less than $6 \%$, death occurs in minutes.

In most industrial applications, hydrogen is used as a gas, which is the state of $\mathrm{H}_{2}$ at standard conditions. However, its boiling point is $20.3 \mathrm{~K}\left(-423^{\circ} \mathrm{F}\right)$, which means that both liquid hydrogen and hydrogen gas vaporized from liquid hydrogen have the potential to be very, very cold. Cold hydrogen can result in frostbite and related physiological harm. Likewise, materials vulnerable to cold embrittlement are vulnerable to cryogenic hydrogen and should be avoided in these applications.

Because hydrogen atoms are very small, hydrogen is able to diffuse into other materials with ease, especially at elevated temperatures. The presence of diffused hydrogen in metals can "cause cracking and catastrophic brittle failures at stresses below the yield stress of susceptible materials." (NACE, 2017) NASA (Brown, 1997) encourages the use of aluminum alloys in hydrogen applications, both for their suitability in cryogenic applications and for their minimal susceptibility to hydrogen embrittlement.

However, it is flammability that causes the gravest concerns in regard to the hazards of hydrogen. Hydrogen forms flammable mixtures with air at concentrations between $4 \%$ and $75 \%$ at standard conditions. It forms flammable mixtures with pure oxygen at concentrations between $4 \%$ and $94 \%$, and also burns easily when combined with other oxidizers. It forms flammable mixtures with chlorine, for instance, at concentrations between $5 \%$ and $95 \%$. At $0.02 \mathrm{~mJ}$, it takes considerably less energy to ignite hydrogen than either methane $(0.29 \mathrm{~mJ})$ or gasoline $(0.24 \mathrm{~mJ})$. (Brown, 1997) When hydrogen burns in air or oxygen, it emits light in the violet to ultraviolet range of the spectrum, meaning the flame is colorless. Any color present in a hydrogen flame is the result of impurities.

\section{Hydrogen in Pressure Vessels}

NASA uses liquid hydrogen as a propellant, but most hydrogen is either used or produced in industrial processes in its gaseous form. Hydrogen that is generated as a product of chemical reactions is typically contained in pressure vessels prior to its subsequent distribution. Likewise, hydrogen that is consumed as a reactant is also typically contained in a pressure vessel prior to its use.

\subsection{Why contain hydrogen in a pressure vessel?}

About $95 \%$ of the hydrogen that is produced industrially is a product of steam reforming, where either carbon or hydrocarbons react with water to produce carbon monoxide, carbon dioxide, and hydrogen. (DOE, 2017) A typical reaction is the steam reforming of methane:

$$
\begin{gathered}
\mathrm{CH}_{4}+\mathrm{H}_{2} \mathrm{O} \rightarrow \mathrm{CO}+3 \mathrm{H}_{2} \text { (the reforming reaction) } \\
\mathrm{CO}+\mathrm{H}_{2} \mathrm{O} \rightarrow \mathrm{CO}_{2}+\mathrm{H}_{2} \text { (the water-gas shift reaction) }
\end{gathered}
$$


Most of the remaining hydrogen that is produced industrially is a product of electrolysis. Water can be electrolyzed directly to yield hydrogen and oxygen, but the more economically viable process, used by the chlor-alkali industry, is the electrolysis of brine to yield caustic and chlorine, with hydrogen as a by-product:

$$
2 \mathrm{NaCl}+2 \mathrm{H}_{2} \mathrm{O} \rightarrow 2 \mathrm{NaOH}+\mathrm{Cl}_{2}+\mathrm{H}_{2}
$$

Hydrogen is used in a number of reactions, collectively known as hydrogenation reactions. They vary widely, but are generally catalyzed reactions at relatively high pressures and temperatures.

An important hydrogenation, the basis of the modern fertilizer industry, is the Haber-Bosch process for making ammonia:

$$
\mathrm{N}_{2}+3 \mathrm{H}_{2} \rightarrow 2 \mathrm{NH}_{3}
$$

There are also several hydrogenation reactions used in the petrochemical industry. These include hydrodealkylation, hydrodesulfurization, and hydrocracking. The hydrodealkylation reaction removes alkyl groups from aromatic compounds leaving the basic aromatic compound, e.g. the hydrodealkylation of toluene to benzene, yielding methane as a by-product:

$$
\mathrm{C}_{6} \mathrm{H}_{5} \mathrm{CH}_{3}+\mathrm{H}_{2} \rightarrow \mathrm{C}_{6} \mathrm{H}_{6}+\mathrm{CH}_{4}
$$

The hydrodesulfurization reaction removes the sulfur in sulfur-containing compounds as hydrogen sulfide, leaving desulfurized hydrocarbons, e.g. the hydrodesulfurization of ethylthiol to ethane:

$$
\mathrm{C}_{2} \mathrm{H}_{5} \mathrm{SH}+\mathrm{H}_{2} \rightarrow \mathrm{C}_{2} \mathrm{H}_{6}+\mathrm{H}_{2} \mathrm{~S}
$$

The cracking reaction splits high molecular weight hydrocarbons into lower molecular weight hydrocarbons, typically of higher economic value:

$$
\mathrm{C}_{\mathrm{n}} \mathrm{H}_{2 \mathrm{n}+1}-\mathrm{C}_{\mathrm{m}} \mathrm{H}_{2 \mathrm{~m}+1}+\mathrm{H}_{2} \rightarrow \mathrm{C}_{\mathrm{n}} \mathrm{H}_{2 \mathrm{n}+2}+\mathrm{C}_{\mathrm{m}} \mathrm{H}_{2 \mathrm{~m}+2}
$$

The hydrogenation reaction familiar to most people, at least by reputation, is the hydrogenation of polyunsaturated vegetable oils to form saturated or monounsaturated fats. Polyunsaturated vegetable oils are liquid and do not provide the same quality of baked goods that solid or semisolid fats provide, and hydrogenated vegetable oil — shortening — is less expensive than natural fats, such as lard or tallow.

So, there are a number of reactions that either generate or use hydrogen, in a number of different industries. In most of these processes, there is a point at which hydrogen is stored in a vessel, and because it is gas, the amount of hydrogen that can be stored in a vessel of a given size increases in proportion to the pressure at which it is stored. Understanding the implications of containing gaseous hydrogen in pressure vessels is paramount to containing that hydrogen safely.

\subsection{Hydrogen deflagration in a pressure vessel}

A common concern associated with hydrogen contained in pressure vessels is the potential for a flammable mixture to form and then deflagrate upon ignition, leading to a catastrophic failure of the vessel and resulting in an explosion with attendant shock waves and blast fragments. 
Forming a flammable mixture is relatively simple. While any oxidizing gas can form a flammable mixture with hydrogen, the gas of most common concern is air. With a flammability range at standard conditions of between $4 \%$ and $75 \%$ hydrogen, the amount of air that has to leak into a hydrogen vessel to form a flammable mixture is not much and the amount of hydrogen that has to leak into a vessel containing air is even less.

Fortunately, hydrogen systems are normally at pressures well above atmospheric pressure, meaning that a system leak is more likely to release hydrogen into the atmosphere than to introduce air into the system. Not that a hydrogen leak into the atmosphere is without consequence. Hydrogen ignites very easily and has a flame that is generally invisible to the human eye, so a hydrogen fire outside of a hydrogen system may not be detected and so remain quite hazardous for an extended period of time. However, it does not have the same issue of confined deflagration leading to a catastrophic vessel failure.

\subsection{Strategies to prevent harmful hydrogen deflagrations in a pressure vessel}

A hydrogen deflagration in a pressure vessel first requires the introduction of the oxidizing gasair - into the vessel to form a flammable mixture. While a leak will not typically be sufficient, there are other mechanisms that can introduce air into a hydrogen vessel. For instance, an actuated vent to atmosphere on a hydrogen vessel may fail open or open spuriously, leading to the ingress of air during a point in the process cycle when the system pressure is low. Another scenario is that air may be introduced during maintenance or an outage and then be purged inadequately before restarting the process. So the first step in a strategy to prevent harmful hydrogen deflagrations in a pressure vessel is to have controls, both engineering and administrative, to reduce the likelihood of forming a flammable mixture.

With the formation of a flammable mixture, ignition of the mixture is relatively easy. All of the usual measures - bonding and grounding, hazardous area classification, prohibition of open flames - are valuable, so the second step in a strategy to prevent harmful hydrogen deflagrations in a pressure vessel is have to have controls, again both engineering and administrative, to reduce sources of ignition. With an ignition energy of just $0.02 \mathrm{~mJ}$, hydrogen should be treated as though all energy sources are high energy ignition sources. If ever the adage, "Regarding the fire triangle, given a fuel and an oxidizer, assume the ignition source is free," was true, it is with hydrogen.

The third step in a strategy to prevent harmful hydrogen deflagrations in a pressure vessel is to design the vessel so that it can contain the deflagration without doing harm. During a hydrogen deflagration in a vessel, the pressure suddenly increases. The pressure increase is not infinite, though. Because the pressure increase is finite, there is a maximum pressure a vessel will reach during a deflagration, and it is possible to design a vessel to contain that pressure while resulting in no more harm than is tolerable. Designing a vessel to contain the deflagration pressure, $\mathrm{P}_{\mathrm{EX}}$, requires knowing two things:

* What will the PEx of a deflagration be?

* What vessel design pressure will contain the $\mathrm{P}_{\mathrm{EX}}$ while resulting in no more harm than is tolerable? 


\section{Effect of Pressure and Temperature on Hydrogen Explosivity Properties}

Schroeder and Holtappels (2005) looked at the explosion characteristics of hydrogen mixtures, both in air and in oxygen. They examined upper and lower explosive limits (LEL and UEL) and $P_{\text {EX }}$. In particular, they studied the effect of pressure and temperature on LEL and UEL and the effect of pressure, temperature, and gas mixture composition on $\mathrm{P}_{\mathrm{EX}}$. This paper is especially interested in the work they reported on mixtures of hydrogen and air.

\subsection{Lower and upper explosive limits}

For gases and vapors that can burn, there is a concentration that is too low or "lean" to support combustion. Likewise, there is a concentration that is too high or "rich" to support combustion. The reported values of "Lower Explosive Limit" and "Upper Explosive Limit" refer specifically to these concentrations, in air, when measured at atmospheric pressure and room temperature, using a specified test method such as ASTM E681 (2015), DIN 51649-1 (1986), or EN 1839 (2017). The concentrations are expressed as volume percent, which corresponds to mole fraction.

Explosive limits are dependent on temperature and pressure, as well as on the specific test method. While the effects follow general trends, hydrogen is peculiar and the work by Schroeder and Holtappels examined the effect of temperature and pressure on its explosive limits.

Their study of the influence of temperature used a method adapted from DIN 51649-1.

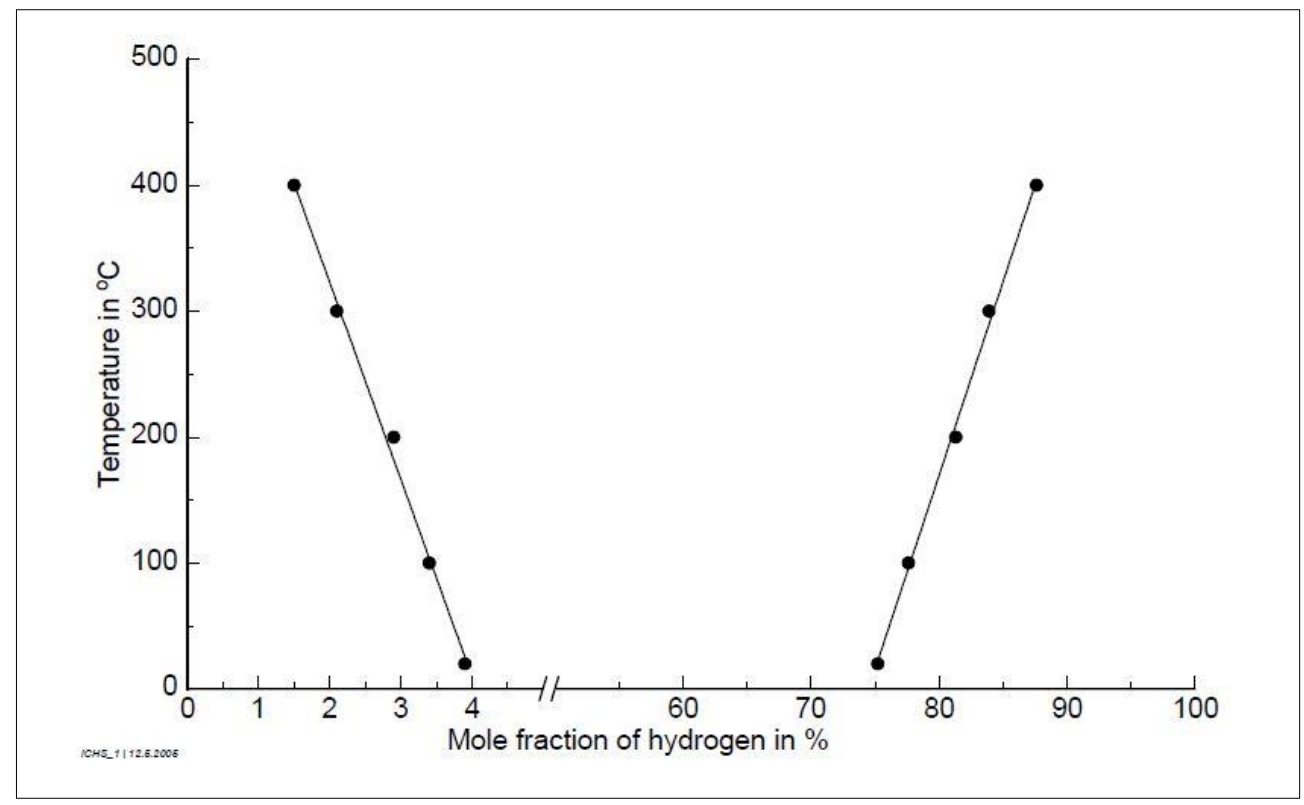

Figure 1. Effect of temperature on explosive limits of hydrogen-air mixtures (Schroeder and Holtappels, 2005).

Unsurprisingly, the explosive limits, already very wide for hydrogen, get wider as the temperature increases. The relationship is extraordinarily linear, as shown in Figure 1. With temperature, $\mathrm{T}$, expressed as $\mathrm{C}$ :

$$
\mathrm{LEL}_{\mathrm{T}}=4.1 \mathrm{~mol} \% \cdot\left[1-0.00157 \mathrm{C}^{-1} \cdot \mathrm{T}\right]
$$




$$
\mathrm{UEL}_{\mathrm{T}}=74.5 \mathrm{~mol} \% \cdot\left[1+0.00044 \mathrm{C}^{-1} \cdot \mathrm{T}\right]
$$

In regard to safety, the flammable limits of hydrogen mixtures widen and so become more dangerous as their temperature increases. However, they are already so wide that little is to be gained from trying to avoid being within the flammable limits by keeping operating temperatures as low as possible.

Their study of the influence of pressure on the flammable limits of hydrogen-air mixtures used a method adapted from the "B" test in EN 1839.

Unlike temperature, the safety effect of increased pressure is negligible to slightly advantageous, as is shown in Figure 2. Increased pressure slightly narrows the explosive limits. Again, though, the limits remain so wide that little is to be gained from trying to avoid being outside of the flammable limits by means of operating at higher pressures.

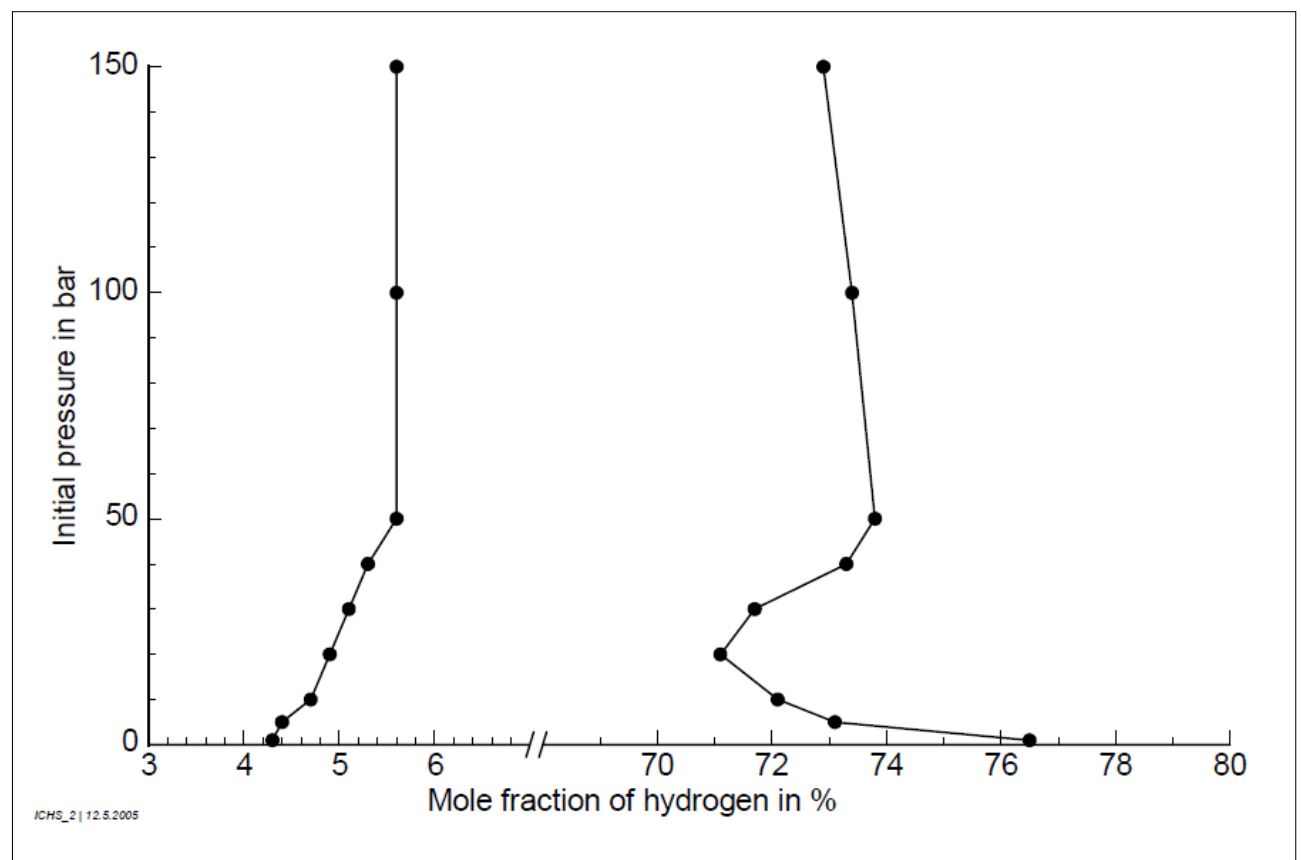

Figure 2. Effect of initial pressure on explosive limits of hydrogen-air mixtures, measured at room temperature (Schroeder and Holtappels, 2005).

\subsection{Explosion pressure ratio}

The explosivity property of hydrogen that is of far greater interest in the design and use of pressure vessels is $\mathrm{P}_{\mathrm{EX}}$, which corresponds to the final pressure in a vessel following a deflagration. The work of Schroeder and Holtappels (2005) demonstrates that the normalized explosion pressure, expressed as the ratio of the absolute explosion pressure to the initial absolute pressure in the vessel, $\mathrm{P}_{\mathrm{EX}} / \mathrm{P}_{\mathrm{O}}$, is highly dependent on the initial composition of the gas mixture but is essentially independent of the initial pressure of the gas mixture. This relationship is shown below in Figure 3. 


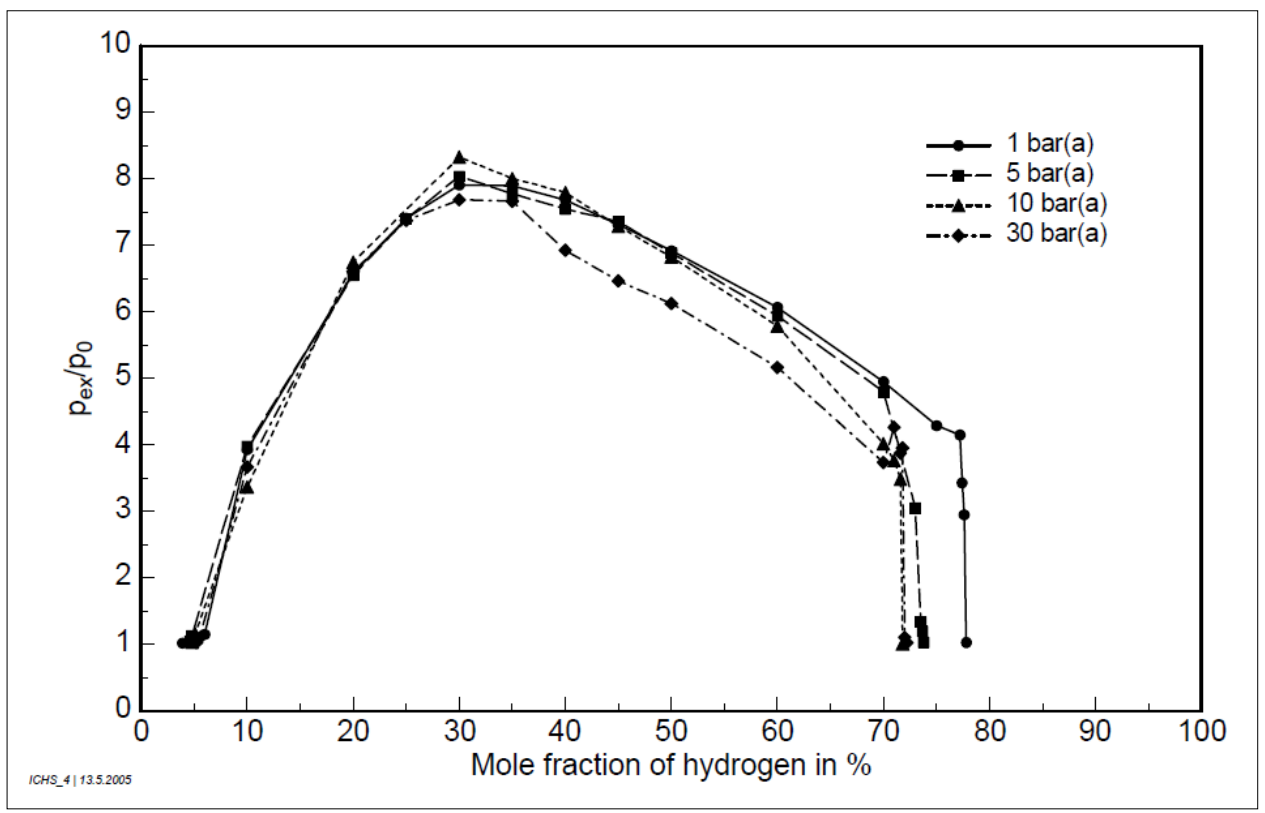

Figure 3. Effect of initial pressure on explosive pressure ratio of hydrogen-air mixtures, measured at room temperature (Schroeder and Holtappels, 2005).

A stoichiometric mixture of hydrogen and air contains $29.6 \mathrm{~mol} \%$ hydrogen in air. It is no coincidence that the peak $\mathrm{P}_{\mathrm{EX}} / \mathrm{P}_{\mathrm{O}}$ corresponds to this composition. At this composition, the combustion reaction consumes all available reactants. Likewise, it is no coincidence that there is no increase in pressure - that $\mathrm{P}_{\mathrm{EX}} / \mathrm{P}_{\mathrm{O}}$ is unity - at the compositions that correspond to the LEL and to the UEL. At these compositions, no combustion reaction can occur at all. If no explosion can occur, then the pressure cannot increase.

Finally, the work of Schroeder and Holtappels (2005) also demonstrates that like the LEL and the UEL, $\mathrm{P}_{\mathrm{EX}} / \mathrm{P}_{\mathrm{O}}$ is also highly dependent on the initial temperature of the gas mixture. Perhaps counter intuitively however, $\mathrm{P}_{\mathrm{EX}} / \mathrm{P}_{\mathrm{O}}$ decreases as the initial temperature of the gas mixture increases. This effect is shown below in Figure 4. 


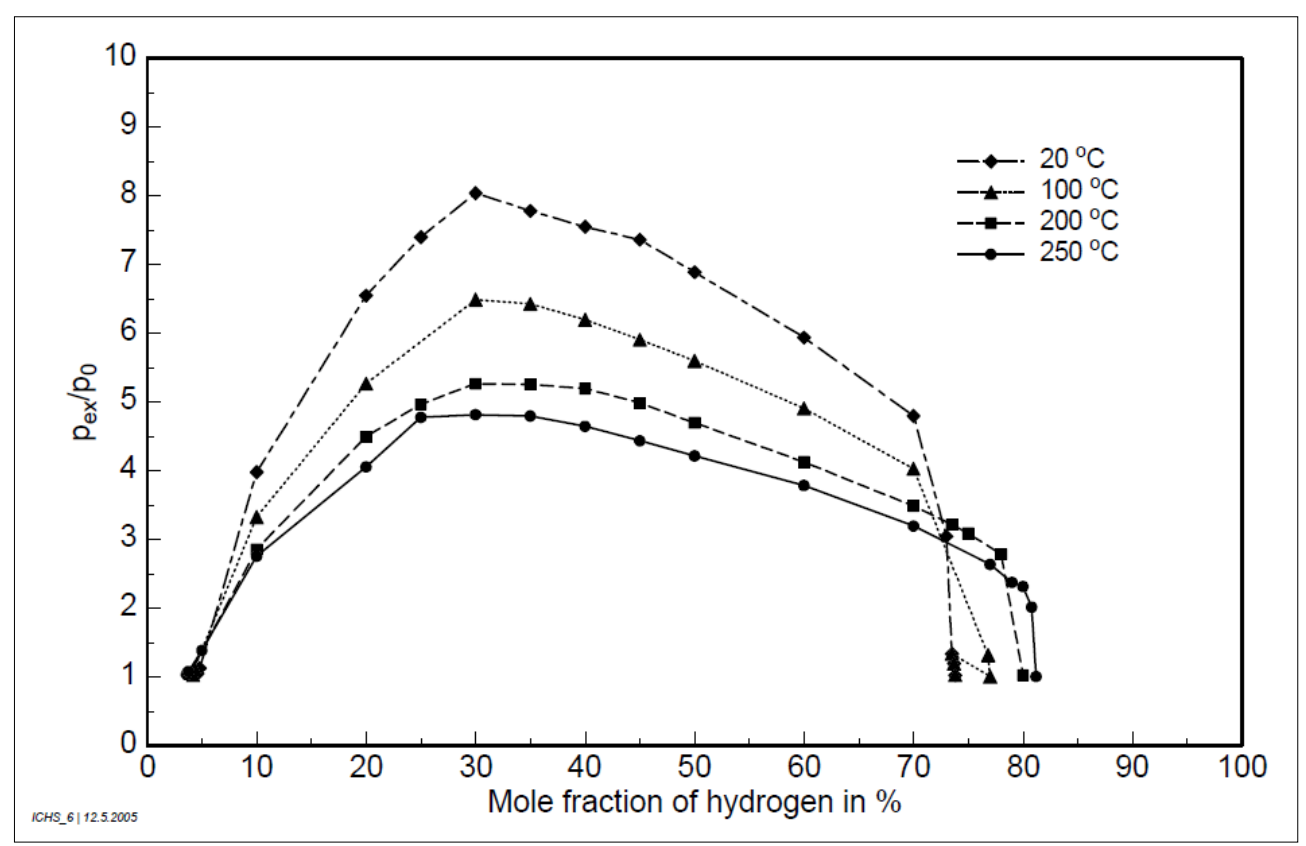

Figure 4. Effect of initial temperature on explosive pressure ratio of hydrogen-air mixtures, with initial pressure at 10 bar (Schroeder and Holtappels, 2005).

Between 10 mol\% hydrogen and 70 mol\% hydrogen, the data is well behaved. The $\mathrm{P}_{\mathrm{EX}} / \mathrm{P}_{\mathrm{O}}$ at a given mole fraction of hydrogen in air is almost perfectly correlated to the inverse of the temperature, expressed in $\mathrm{K}^{-1}$, and converges on a value of unity, or no pressure increase upon explosion, as the temperature approaches infinity. Figure 5 recasts the data from Figure 4, showing $\mathrm{P}_{\mathrm{EX}} / \mathrm{P}_{\mathrm{O}}$ as a function of inverse temperature. 


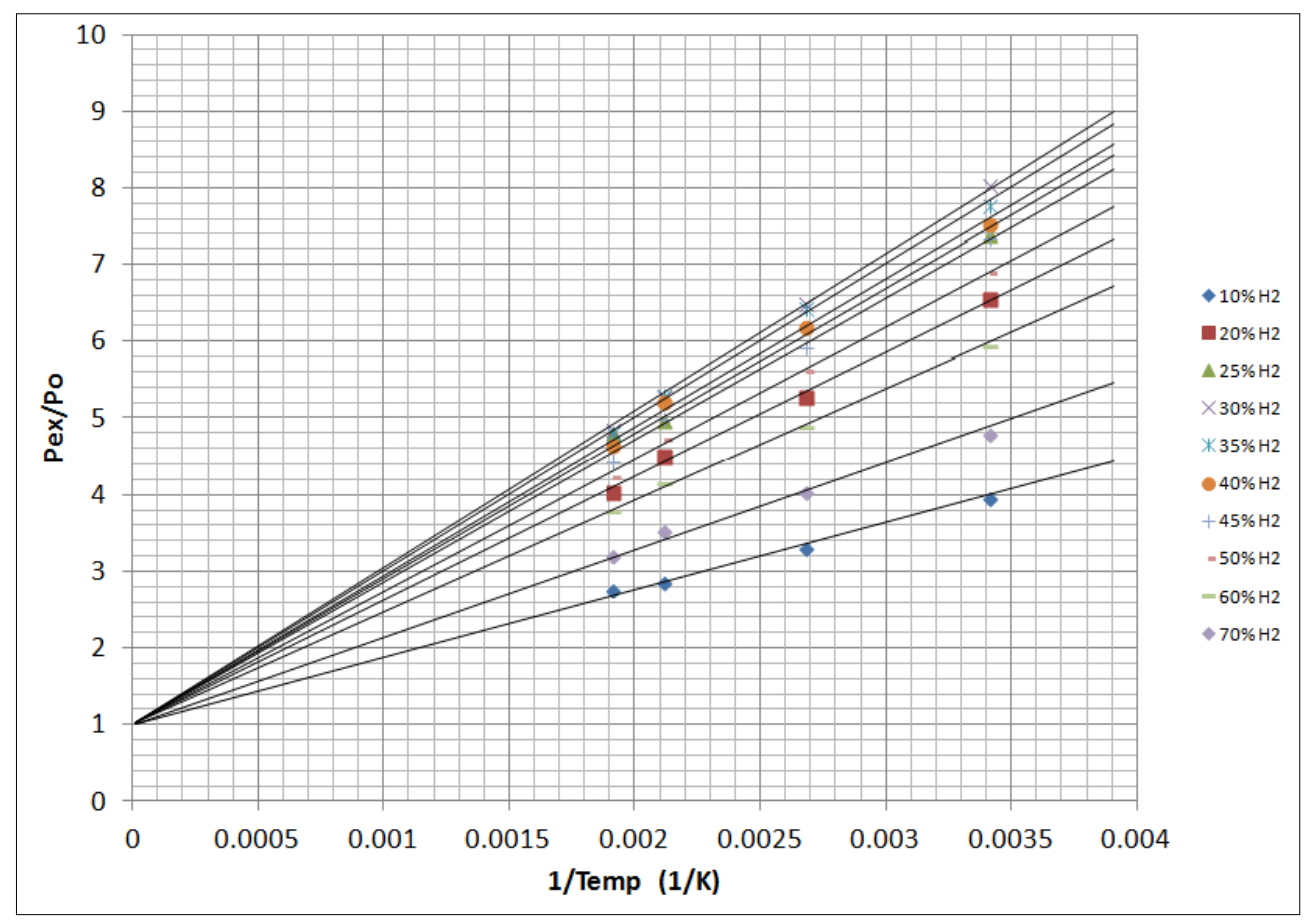

Figure 5. Effect of inverse initial temperature on explosive pressure ratio of hydrogen-air mixtures between $10 \mathrm{~mol} \%$ and $70 \mathrm{~mol} \%$.

The functions shown in Figure 5 are highly correlated. The coefficient of determination, $\mathrm{R}^{2}$, for each data set is greater than 0.985 in all cases.

Table 1. Correlation of $\mathrm{P}_{\mathrm{EX}} / \mathrm{P}_{\mathrm{O}}$ to Inverse Temperature as a Function of Composition

\begin{tabular}{|c|c|c|}
\hline $\begin{array}{c}\text { Hydrogen-Air } \\
\text { Mixture }\end{array}$ & $\begin{array}{c}\text { Correlation } \\
\text { (T in K) }\end{array}$ & $\mathbf{R}^{\mathbf{2}}$ \\
\hline $10 \mathrm{~mol} \% \mathrm{H}_{2}$ & $\mathrm{P}_{\mathrm{EX}} / \mathrm{P}_{\mathrm{O}}=1+877.3 \mathrm{~K}^{-1} / \mathrm{T}$ & 0.9866 \\
\hline $20 \mathrm{~mol} \% \mathrm{H}_{2}$ & $\mathrm{P}_{\mathrm{EX}} / \mathrm{P}_{\mathrm{O}}=1+1619.9 \mathrm{~K}^{-1} / \mathrm{T}$ & 0.9953 \\
\hline $25 \mathrm{~mol} \% \mathrm{H}_{2}$ & $\mathrm{P}_{\mathrm{EX}} / \mathrm{P}_{\mathrm{O}}=1+1898.7 \mathrm{~K}^{-1} / \mathrm{T}$ & 0.9915 \\
\hline $30 \mathrm{~mol} \% \mathrm{H}_{2}$ & $\mathrm{P}_{\mathrm{EX}} / \mathrm{P}_{\mathrm{O}}=1+2046.6 \mathrm{~K}^{-1} / \mathrm{T}$ & 0.9986 \\
\hline $35 \mathrm{~mol} \% \mathrm{H}_{2}$ & $\mathrm{P}_{\mathrm{EX}} / \mathrm{P}_{\mathrm{O}}=1+2004.7 \mathrm{~K}^{-1} / \mathrm{T}$ & 0.9975 \\
\hline $40 \mathrm{~mol} \% \mathrm{H}_{2}$ & $\mathrm{P}_{\mathrm{EX}} / \mathrm{P}_{\mathrm{O}}=1+1937.1 \mathrm{~K}^{-1} / \mathrm{T}$ & 0.9954 \\
\hline $45 \mathrm{~mol} \% \mathrm{H}_{2}$ & $\mathrm{P}_{\mathrm{EX}} / \mathrm{P}_{\mathrm{O}}=1+1853.4 \mathrm{~K}^{-1} / \mathrm{T}$ & 0.9964 \\
\hline $50 \mathrm{~mol} \% \mathrm{H}_{2}$ & $\mathrm{P}_{\mathrm{EX}} / \mathrm{P}_{\mathrm{O}}=1+1728.0 \mathrm{~K}^{-1} / \mathrm{T}$ & 0.9976 \\
\hline $60 \mathrm{~mol} \% \mathrm{H}_{2}$ & $\mathrm{P}_{\mathrm{EX}} / \mathrm{P}_{\mathrm{O}}=1+1461.6 \mathrm{~K}^{-1} / \mathrm{T}$ & 0.9976 \\
\hline $70 \mathrm{~mol} \% \mathrm{H}_{2}$ & $\mathrm{P}_{\mathrm{EX}} / \mathrm{P}_{\mathrm{O}}=1+1137.3 \mathrm{~K}^{-1} / \mathrm{T}$ & 0.9852 \\
\hline
\end{tabular}

Figure 6 shows a plot of correlation coefficients, K, as a function of the composition of hydrogen-air mixtures for the relationship

$$
\mathrm{P}_{\mathrm{EX}} / \mathrm{P}_{\mathrm{O}}=1+\mathrm{K} / \mathrm{T}
$$

where $\mathrm{T}$ is expressed as absolute temperature, $\mathrm{K}$. 


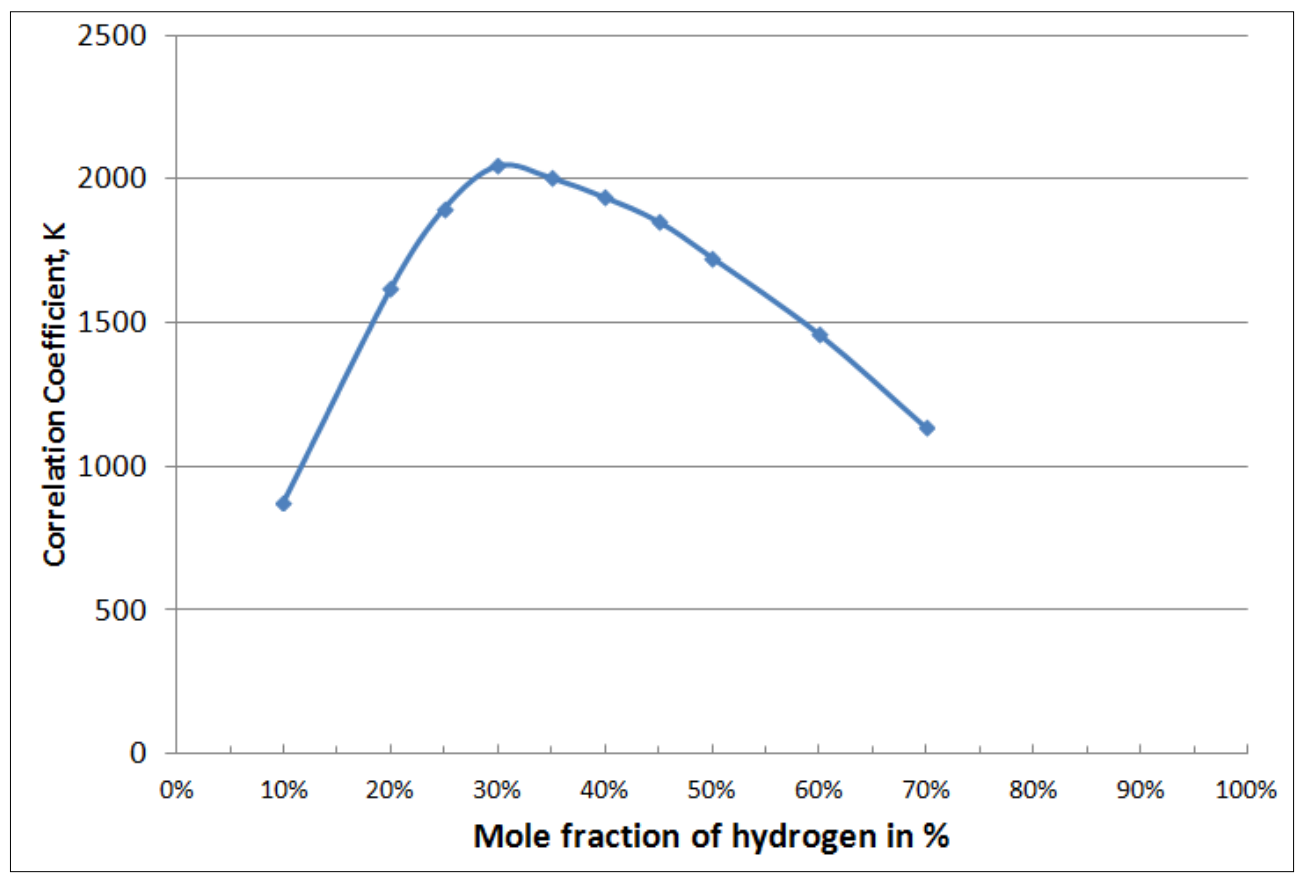

Figure 6. Correlation coefficients as a function of the composition of hydrogen-air mixtures for the relationship, $\mathrm{P}_{\mathrm{EX}} / \mathrm{P}_{\mathrm{O}}=1+\mathrm{K} / \mathrm{T}$

The value of $\mathrm{K}$ from the plot in Figure 6 for a specific composition of hydrogen-air mixture can be used to determine the $\mathrm{P}_{\mathrm{EX}} / \mathrm{P}_{\mathrm{O}}$ for a process operating at a specific temperature. Given a particular $\mathrm{P}_{\mathrm{O}}$, the $\mathrm{P}_{\mathrm{EX}}$ can be calculated to answer the first question from above: What will the $\mathrm{P}_{\mathrm{EX}}$ of a deflagration be?

Most conservatively, the peak $\mathrm{P}_{\mathrm{EX}} / \mathrm{P}_{\mathrm{O}}$ occurs when the composition of the hydrogen-air mixture is a perfectly stoichiometric mixture: $29.6 \mathrm{~mol} \%$ hydrogen. For a stoichiometric mixture, $\mathrm{K}$ is 2050. Using this value is conservative, given that the probability of inadvertently forming a perfect stoichiometric mixture of hydrogen and air is fairly low; a near perfect stoichiometric mixture, requiring a $\mathrm{K}$ of 2000 or greater, spans $7 \%$ of the range of hydrogen-air mixtures, from $28 \mathrm{~mol} \%$ hydrogen to $35 \mathrm{~mol} \%$ hydrogen.

\section{Consequences of Vessel Overpressure}

Pressure vessels are designed with a Maximum Allowable Working Pressure (MAWP). As the term suggests, vessels can operate at pressures up to the MAWP, but should never be operated at a pressure above the MAWP. (ASME, 2017) Beginning with this, the most conservative approach to answering the question, "What vessel design pressure will contain the $\mathrm{P}_{\mathrm{EX}}$ while resulting in no more harm than is tolerable?" would be to assure that a vessel has a MAWP greater than the PEX. This approach, however, is overly conservative.

The ASME Boiler and Pressure Vessel Code, the BPVC (2017), acknowledges that some flexibility is required when operating pressure vessels at or near their MAWP. For instance, the design of relief systems allows for a relieving pressure of $110 \%$ of MAWP when the vessel is protected with a single relief device. When there is more than one relief device, the BPVC 
allows a relieving pressure of $116 \%$ of MAWP; for the external fire case, the BPVC allows a relieving pressure of $121 \%$ of MAWP. Clearly, there is a margin above the MAWP where no harm is expected to come to the pressure vessel. A vessel will operate safely at $100 \%$ of MAWP and it will not then fail catastrophically at $101 \%$ of MAWP. In Guidelines for Initiating Events... (Chastain, 2015), the authors indicate their expectation that there will be no consequences at pressures less than $121 \%$ of MAWP.

Pressure vessels are designed to withstand their hydrostatic test pressures. Prior to the publication of the BPVC Addendum in 1999 (ASME, 1999) the pressure at which vessels were hydrostatically tested was $150 \%$ of MAWP. Since 1999, the pressure at which vessels are hydrostatically tested is $130 \%$ of MAWP. This suggests that up to 130 150\% of MAWP, there will be no consequences associated with overpressure.

Above $150 \%$ of MAWP, there is general agreement that the probability of gasket leakage increases to a significant level, but that permanent damage to the vessel is unlikely. So, it is reasonable to expect, with a probability of around $10 \%$, that there will be loss of containment because of gasket leakage. On the other hand, a vessel can be expected to withstand pressures this high without failing. A vessel should be able to contain a deflagration even if its contents leak through a flange.

Above $200 \%$ of MAWP, the probability of gasket leakage increases to near certainty. The probability of permanent damage to the vessel also becomes noteworthy.

\subsection{Permanent vessel damage}

There are primarily three types of permanent damage to pressure vessels as a result of overpressure:
* Permanent vessel deformation
* Ductile failure
* Catastrophic brittle fracture

Permanent vessel deformation results when the internal pressure on the vessel imposes a stress greater than the yield stress of the material. In cylinders, the deformation will be in two directions. Radially, the vessel will expand as a result of "hoop stresses". Simultaneously, axial stress will cause the vessel to contract to compensate. The result will be bulging. An ideal cylinder will bulge symmetrically, but since most vessels have all manner of asymmetrical elements, a real cylinder will bulge unevenly. At low enough pressures, stress resulting from internal pressure will lead to reversible vessel deformation. Above $200 \%$ of MAWP, there is a significant probability of permanent vessel deformation and above $250 \%$ of MAWP, the probability of permanent vessel deformation approaches near certainty. The safety implications are limited to those of a significant leak, but from the perspective of asset integrity, an event that results in permanent vessel deformation will require equipment replacement.

Ductile failure is a tensile failure that occurs when the stresses that cause vessel deformation are increased so that the vessel material is thinned to the point of rupture. While catastrophic in the sense that the vessel will tear apart and suddenly releases its contents, there are not likely to be many fragments launched as projectiles as a result of ductile failure. Likewise, a ductile failure 
will not typically be sufficiently sudden to result in the shockwave typically associated with an "explosion." Above $300 \%$ of MAWP, the probability of ductile failure approaches near certainty.

The safety implications of ductile failure are those associated with a total loss of containment. When the initial contents of the vessel are richer than a stoichiometric mixture, any hydrogen unconsumed in the initial deflagration will be released and be ignited, the vessel failure itself serving as the ignition source. The safety implications of a ductile failure are more severe than for a permanent vessel deformation, although the impact zone is likely to be limited to the immediate area of the vessel. Regardless, an event like this will require equipment replacement.

Catastrophic brittle fracture is the almost instantaneous cracking of a vessel, with little indication or warning of ductile degradation before the failure. Unlike ductile failure, the material of construction does not thin before failure, and catastrophic brittle facture results in many projectile fragments and the release of a shockwave. Catastrophic brittle fracture is, in every sense of the word, an "explosion."

The pressure at which catastrophic brittle facture occurs is related to the ultimate yield strength, which the BPVC currently stipulates must have a design margin of 3.5 times that required for the MAWP. In his review of the 1999 Addenda to the BPVC, where ASME changed the design margin for pressure vessels from 4.0 to 3.5, Sperko does an excellent job of summarizing the history of design margins in the BPVC. (2000)

"In the 1999 addenda of the ASME Boiler Code, the design margin (formerly known as the "Safety Factor") was changed from 4.0 to 3.5.

"In the 1915 edition, the margin was 5. It stayed at 5 until 1943 when it was changed to 4 largely to conserve materials during WWII. Immediately after the war, the margin was changed back to 5 . In 1950, the performance of the vessels that had been made using a margin of 4 was reviewed and found satisfactory. As a result, the margin was changed to 4 in 1951."

This design margin - 3.5 for BPVC vessels constructed after 1999, 4.0 for BPVC vessels constructed between 1951 and 1999 - is also the design margin used to calculated the explosive energy released by a vessel rupture, based on the stated MAWP of the vessel. A different rule should be applied to pressure vessels designed and fabricated in compliance with the European Pressure Equipment Directive or the Unfired Pressure Vessel standard, EN 13445 (2014). McKetta noted that the European PED assumes a safety factor of 4, but based on only two-thirds of the yield strength of the materials used. (1993) This means that the burst pressure for European PED pressure vessels should be assumed to be at least 4 / 2/3, or 6, times the MAWP of the vessel.

\subsection{Risk of vessel overpressure}

As process risk analysts are fond of pointing out, risk consists of two components: consequence severity and likelihood. In a given overpressure event, it is important to associate the impact of the event - its severity - with the likelihood of that impact. There are a number of tables available. Below is the table that the author has found to be reasonable, being neither overly conservative nor unduly tolerant. 
Table 2. Probability of Consequences Associated with Vessel Overpressure

\begin{tabular}{|c|c|c|l|}
\hline Overpressure & $\begin{array}{c}\text { Probability of } \\
\text { Catastrophic } \\
\text { Vessel Failure }\end{array}$ & $\begin{array}{c}\text { Probability } \\
\text { of Gasket or } \\
\text { Seal Failure }\end{array}$ & Most Likely Consequence \\
\hline Up to $1.5 \times$ MAWP & $10^{-5}$ & $10^{-2}$ & $\begin{array}{l}\text { No permanent damage to vessel. } \\
\text { Gasket leakage unlikely. }\end{array}$ \\
\hline Up to 2.0 x MAWP & $10^{-4}$ & $10^{-1}$ & $\begin{array}{l}\text { No permanent damage to vessel. } \\
\text { Gasket leakage likely. }\end{array}$ \\
\hline Up to $2.5 \times$ MAWP & $10^{-3}$ & 1 & $\begin{array}{l}\text { Likely permanent vessel } \\
\text { deformation. Gasket failure. }\end{array}$ \\
\hline Up to $3.0 \times$ MAWP & $10^{-2}$ & 1 & $\begin{array}{l}\text { Deformation leading to release. } \\
\text { Gasket failure. }\end{array}$ \\
\hline Up to $3.5 \times$ MAWP & $10^{-1}$ & 1 & $\begin{array}{l}\text { Ductile failure, but not catastrophic } \\
\text { brittle failure }\end{array}$ \\
\hline Over $3.5 \times$ MAWP & 1 & 1 & $\begin{array}{l}\text { Catastrophic brittle failure, resulting } \\
\text { in fragment projectiles, shockwave }\end{array}$ \\
\hline
\end{tabular}

\section{Designing to Reduce Risk}

It is possible to design a pressure vessel to contain a hydrogen deflagration. It is necessary to understand the consequences to be averted, and the conditions under which the deflagration will occur.

\subsection{Consequences to avert}

The consequences of a hydrogen deflagration that need to be averted can range from material release and equipment damage to a catastrophic brittle failure with resulting fragment projectiles and shockwave. The impact of concern will be an important factor when considering the design of the pressure vessel.

When the consequence to avert is material release or equipment damage of any type, the design of the pressure vessel must be such that a deflagration will not result in an overpressure greater than 1.5 x MAWP.

When the consequence to avert is permanent damage to the vessel itself, the design of the pressure vessel must be such that a deflagration will not result in an overpressure greater than $2.0 \times$ MAWP.

In many cases, the consequence to avert is injury to employees in the area. In these cases, permanent vessel deformation is acceptable, provided that the vessel contains the deflagration. Following the event, however, the vessel will have to be replaced. In these cases, the design of the pressure vessel must be such that a deflagration will not result in an overpressure greater than $2.5 \times$ MAWP. 
When the consequence to avert is fatalities in the immediate area of the vessel, then it is important to avoid ductile failure. The design of the pressure vessel must be such that a deflagration will not result in an overpressure greater than 3.0 x MAWP.

When the consequence to avert is the extreme case of a vessel explosion with resulting fragment projectiles and shockwave that will have an impact over an extensive zone beyond the immediate area of the vessel, then it is important to avoid catastrophic brittle failure. The design of the pressure vessel must be such that a deflagration will not result in an overpressure greater than $3.5 \times$ MAWP.

Occupancy factors, operating approach, and philosophy about assets as impact vectors will all play a role in determining what consequence is to be averted.

\subsection{Conditions under which the deflagration will occur}

Hydrogen deflagration overpressure in a pressure vessel depends on three variables: the composition of the hydrogen-air mixture, the temperature of the hydrogen-air mixture, and the initial pressure in the pressure vessel at the time of the deflagration. To the extent these are known for a given scenario, the $\mathrm{P}_{\mathrm{EX}}$ can be calculated and the appropriate MAWP for the pressure vessel specified. Conversely, for a given vessel, the $\mathrm{P}_{\mathrm{EX}}$ can be managed by managing the conditions at which a deflagration might occur.

The $\mathrm{P}_{\mathrm{EX}}$ of a hydrogen deflagration increases as the hydrogen-air mixture approaches a stoichiometric composition, either from a lean mixture or from a rich mixture. To the extent that a process can be controlled to avoid mixtures with a stoichiometric composition, the risk is reduced. As a risk-reduction strategy, however, this is the weakest. For the most part, operations avoid mixtures of hydrogen and air at any composition, so any hydrogen-air mixture is typically inadvertent. To pretend that the composition of a mixture that is made inadvertently can be controlled is probably delusional. So, while it is fair to expect that an inadvertent hydrogen-air mixture will not be perfectly stoichiometric, it is equally reasonable to assume that any such mixture should be treated as a stoichiometric mixture. This means that for inadvertent hydrogenair mixtures over which there is no control of composition, the relationship to use to calculate $\mathrm{P}_{\mathrm{EX}} / \mathrm{P}_{\mathrm{O}}$ is

$$
\mathrm{P}_{\mathrm{EX}} / \mathrm{P}_{\mathrm{O}}=1+2050 \mathrm{~K}^{-1} / \mathrm{T}
$$

where $\mathrm{T}$ is in $\mathrm{K}$.

The $\mathrm{P}_{\mathrm{EX}}$ of a hydrogen deflagration decreases as the temperature of the hydrogen-air mixture increases. To the extent processes can be run at higher temperatures, the risk is reduced. As a risk-reduction strategy, this may or may not be applicable, but where it is applicable, it can be effective.

The $\mathrm{P}_{\mathrm{Ex}}$ of a hydrogen deflagration decreases as the pressure of the hydrogen-air mixture decreases. It is directly proportional. To the extent processes can be run at lower pressures, the risk is reduced. Wherever this risk-reduction strategy is applicable, it is very effective. 


\subsection{An example}

A dehydrogenation process yields an aqueous solution of product and gaseous hydrogen at a pressure slightly above atmospheric and at a temperature of around $40 \mathrm{C}$. The hydrogen is collected and flared. Plant lore says that as long as all of the hydrogen equipment is designed with a 50 psig MAWP, any deflagration in the equipment will be contained, although the equipment will need to be carefully inspected after a deflagration event and may need to be replaced. No one recalls the basis for the 50 psig design criteria.

Any mixture of hydrogen and air would be inadvertent, so the correct relationship to use for calculating $\mathrm{P}_{\mathrm{EX}} / \mathrm{P}_{\mathrm{O}}$ is for a stoichiometric mixture. The operating temperature, $\mathrm{T}$, is $40 \mathrm{C}$, or 313.2 K. So

$$
\mathrm{P}_{\mathrm{EX}} / \mathrm{P}_{\mathrm{O}}=1+2050 \mathrm{~K}^{-1} / \mathrm{T}=1+2050 \mathrm{~K}^{-1} / 313.2 \mathrm{~K}=7.55
$$

The operating pressure, $\mathrm{P}_{\mathrm{O}}$, is slightly above atmospheric pressure at around 15 psia. So

$$
\mathrm{P}_{\mathrm{EX}}=7.55 \cdot \mathrm{P}_{\mathrm{O}}=7.55 \cdot 15 \mathrm{psia}=113.25 \mathrm{psia}=98.55 \mathrm{psig}
$$

Given an MAWP for hydrogen equipment of 50 psig, the PEX converts to $1.97 \mathrm{x}$ MAWP. This is right at the boundary between a consequence of "No permanent damage to vessel. Gasket leakage likely." and "Likely permanent vessel deformation. Gasket failure." In this case, the analysis supports plant lore, but the plant lore should be replaced with a formal analysis.

\section{Going Forward}

There are a wide variety of processes that depend on containing hydrogen in a pressure vessel. Process hazard analyses of these processes frequently conclude that a deflagration of an inadvertent mixture of a hydrogen-air mixture is a hazard that must be addressed. An overly simple and overly conservative approach is to assume that any overpressure resulting from a deflagration will cause a catastrophic vessel failure resulting in injuries and fatalities, as well as asset loss and lost time.

The work of Schroeder and Holtappels and others allows us to move beyond that overly simple and overly conservative approach. Hydrogen-air deflagrations, like other process safety concerns, are scenarios that can be analyzed and addressed with engineering.

\section{Abbreviations and Acronyms}

ASME: American Society of Mechanical Engineers

ASTM: American Society for Testing and Materials

BPVC: $\quad$ Boiler and Pressure Vessel Code

DIN: $\quad$ Deutsches Institut für Normung (German Standards Institute)

EN: $\quad$ Europäische Norm (European Standard)

LEL: $\quad$ Lower explosive limit, mol\% or vol\%

LEL $L_{T}$ Lower explosive limit at temperature, $\mathrm{T}$

MAWP: Maximum Allowable Working Pressure

NASA: National Aeronautics and Space Administration 
PED: $\quad$ Pressure Equipment Directive

$P_{\mathrm{EX}}: \quad$ Deflagration pressure, absolute

$\mathrm{P}_{\mathrm{O}}$ : $\quad$ Initial pressure, absolute

UEL: $\quad$ Upper explosive limit, mol\% or vol\%

UELT: $\quad$ Upper explosive limit at temperature, $\mathrm{T}$

\section{References}

ASME (1999), Boiler and Pressure Vessel Code Section VIII-Rules for Construction of Pressure Vessels, American Society of Mechanical Engineers, New York, https://www.asme.org/ .

ASME (2017), Boiler and Pressure Vessel Code Section VIII-Rules for Construction of Pressure Vessels, Division 1, ASME International, New York, https://www.asme.org/.

ASTM E681-09 (2015), Standard Test Method for Concentration Limits of Flammability of Chemicals (Vapors and Gases), ASTM International, West Conshohocken, PA, https://www.astm.org .

Brown, William J. et al. (12-Feb-1997), Safety Standard for Hydrogen and Hydrogen Systems: Guidelines for Hydrogen System Design, Materials Selection, Operations, Storage, and Transportation, Office of Safety and Mission Assurance, National Aeronautics and Space Administration, Washington, DC. 390 pp. Accessed at https://ntrs.nasa.gov/archive/nasa/casi.ntrs.nasa.gov/19970033338.pdf on 05-Aug-2017.

Chastain, Wayne., et al. (2015). Guidelines for Initiating Events and Independent Protection Layers in Layer of Protection Analysis. New York: Center for Chemical Process Safety of the AIChE. New York.

CSN EN 1839 ed. 2 (2017), Determination of Explosion Limits and Limiting Oxygen Concentration (LOC) for Flammable Gases and Vapours, European Committee for Standardization (CEN), Brussels. https://www.cen.eu .

CSN EN 13445 (2014), Unfired Pressure Vessels, European Committee for Standardization (CEN), Brussels. https://www.cen.eu .

DIN 51649-1 (01-Dec-1986), Determination of Explosion Limits of Gases and Gas/Air Mixtures, Deutsches Institut für Normung e.V., Berlin., https://www.din.de/en .

DOE (2017), Hydrogen Production: Natural Gas Reforming, Office of Energy Efficiency \& Renewable Energy, United States Department of Energy, Washington, DC. Accessed at https://energy.gov/eere/fuelcells/hydrogen-production-natural-gas-reforming on 05-Aug-2017.

McKetta, John J. (1993) Encyclopedia of Chemical Processing and Design, Vol. 42, Marcel Dekker, New York. p.214.

NACE (2017), Hydrogen Embrittlement, NACE International, Houston, TX. Accessed at https://www.nace.org/Corrosion-Central/Corrosion-101/Hydrogen-Embrittlement/ on 05-Aug2017. 
Schroeder, V. and K. Holtappels (2005-Sep-08), Explosion Characteristics of Hydrogen-Air and Hydrogen-Oxygen Mixtures at Elevated Pressures. Proceedings of the International Conference on Hydrogen Safety, held in Pisa, Italy. Accessed at http://conference.ing.unipi.it/ichs2005/Papers/120001.pdf on 20-Jan-2017.

Sperko, Walter J. (2000-Jun-01), Reduction of Design Margin in the ASME Boiler and Pressure Vessel Code in the 1999 Addenda, Sperko Engineering Services Inc., Greensboro, NC. Accessed at http://www.sperkoengineering.com/html/articles/Margin.pdf on 05-Aug-2017. 